\title{
What does it take to forgive? Predictors of forgiveness among Filipino late adolescents
}

De Leon, Monica Sophia L. $\bowtie$

University of Santo Tomas, Philippines

Ateneo de Manila University, Philippines (moxdeleon@gmail.com)

Lopez, Gilda D.

Ateneo de Manila University, Philippines (gilda4th@gmail.com)

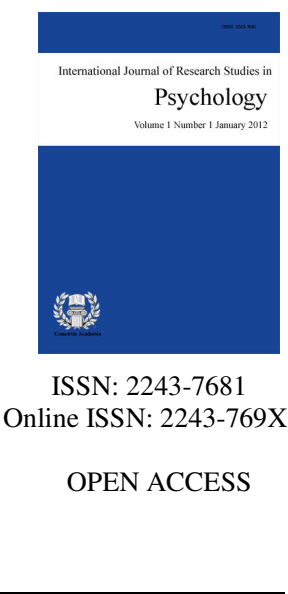

Received: 9 December 2016

\section{Abstract}

Forgiveness can be a bridge to help restore relationships beset by bitterness and resentment caused by interpersonal offenses. What factors hinder forgiveness and what facilitate it? This study examined closely the factors that predict forgiveness using structural equation modeling. An integrated model of forgiveness in close relationships was tested among Filipino college students $(\mathrm{N}=1200)$ in Metro Manila who are between 16 to 22 years old. The factors were categorized according to: impact on self (perceived severity, negative emotions, rumination and attribution); offender's behavior (acknowledging the offense and making amends); relationship (quality of relationship, commitment, and sense of indebtedness or utang na loob); and spirituality. Forgiveness was significantly predicted by empathy and impact on self but not spirituality. Together, the predictors explain $49 \%$ of the variance in forgiveness. Empathy which was found to be the strongest predictor of forgiveness was further predicted by offender's behavior after the offense and relationship. The factors were also found to be significantly correlated with each other. The findings of this study imply that empathy should be strongly encouraged among Filipinos to facilitate forgiveness.

Keywords: forgiveness; late adolescents; empathy; personal relationships; spirituality 


\section{What does it take to forgive? Predictors of forgiveness among Filipino late adolescents}

\section{Introduction}

Relationships can inevitably entail conflicts and offenses that oftentimes result to the offended person's nurtured feelings of anger, resentment, antagonism and hate for the perceived wrong done. An adolescent's stance, for example, can become callous and cold against the offender who could be one's family members, former closest friends, and significant others. Playing a crucial role in every web of human relationships, forgiveness comes into the picture as a bridge to help alleviate or restore these relationships.

Interpersonal conflicts in family and peer relationships rise during the late adolescence stage. College-age youth, also labeled as "emerging adulthood" and "late adolescence" (Baumbach, Forward, \& Hart, 2006) experience major changes which include increased independence from parents, development of closeness and intimacy in friendship and growing interest in romantic relationship (Seiffge-Krenke, 2011). This developmental period is characterized by increases in internalizing and externalizing problems and negative emotions (Coban, 2013; Hawk, Keijsers, Branje, Graaf, Wied et al., 2013). A number of cases of stress, depression, anxiety involving young people are caused by strained relationships in the family, significant others or among friends. The negative emotions associated with these conflicts seem to affect their self-esteem, academic performance, and other relationships. Thus, there is a need for preventive measures to help these adolescents deal with the hurt that may be brought into other future relationships. Forgiveness may be a way to deal with such interpersonal conflicts. This age group is already capable of having a deeper understanding of forgiveness concepts (Park \& Enright, 1997). Forgiveness appears to be appropriate for college students who are experiencing hurts in their relationships (Subkoviak, Enright, Wu, Gassin, Freedman et al., 1995). Filipino adolescents who went through forgiveness therapy showed decreased levels of anxiety and depression, increased self-esteem and improved thoughts, affect and behavior toward the offender (De Leon, 2008). Investigating the factors that predict forgiveness among these late adolescents may be helpful to better facilitate forgiveness interventions on them.

But how does forgiveness happen? After being deeply hurt by the offense committed by a loved one, a person experiences strong negative feelings such as resentment and bitterness and makes a difficult decision to let go of negative thoughts and attitudes about the offense and the offender. Studies have shown that a person who forgives is less motivated to avoid and take revenge against an offending loved one and more motivated toward benevolence and good will of the offender (McCullough, Worthington, \& Rachal, 1997). But it seems that forgiveness is not easy. It is sometimes a painful process, which not only involves removal of negative emotions towards an offender but also an increase in positive attitudes and behavior toward the offender (Enright, 2001).

What factors hinder forgiveness and what facilitate it? Several studies on forgiveness have examined the different factors associated with it: (a) offense severity (Fincham, Jackson, \& Beach, 2005), (b) empathy (McCullough et al., 1997; Welton, Hill, \& Seybold, 2008; Worthington, 1998), (c) apology (Struthers, Eaton, Santelli, Uchiyama, \& Shirvani, 2008; Szablowinski, 2012), (d) rumination (Wade, Vogel, Liao, \& Goldman, 2008), (e) attribution (Fincham, Paleari, \& Regalia, 2002), (f) quality of relationship (McCullough, Rachal, Sandage, Worthington, Brown et al.,1998) among others. Meta-analyses (Fehr, Gelfand, \& Nag, 2010; Riek \& Mania, 2012) of these factors have been done to examine the antecedents and correlates of interpersonal forgiveness. However, there is a lack of empirical integration in forgiveness literature (Fehr et al., 2010). There has been no study yet that has integrated the important predictors of forgiveness and identified the strengths of each predictor and their relationships with each other.

According to Riek and Mania (2012), future research should explore the antecedents of forgiveness, understand their relationships, and their impact on forgiveness. In meta-analytic studies on forgiveness, it was 
found that there were not enough studies that examined the relationships of determinants of forgiveness at the same time (Fehr et al., 2010; Riek \& Mania, 2012). Factors associated with forgiveness must be examined closely to allow a deeper understanding of how forgiveness happens which can help in improving interventions designed to promote forgiveness. In forgiveness research in the Philippines, some of the pressing issues include the absence of conceptual and theoretical explanations on how Filipinos forgive, the identification of contributing factors of forgiveness and how culture and personality play a role in this experience (Rungduin \& Rungduin, 2013).

This study, thus, aims to investigate the different factors that affect forgiveness by testing a model that incorporates the various theories of forgiveness. Two frameworks on the determinants of forgiveness provide a comprehensive theoretical model on the factors related to forgiveness: social-psychological model of McCullough et al. (1998) and the tripartite forgiveness typology by Fehr et al. (2010). This study hopes to integrate these two frameworks in one model, adapting them to the Filipino culture to determine what facilitates forgiveness among Filipino late adolescents.

\subsection{Frameworks on the determinants of forgiveness}

Social-psychological framework of forgiveness - A theoretical framework by McCullough et al. (1998) provided a social-psychological analysis of interpersonal forgiving and identified the determinants of forgiving in close relationships (see Table 1). They defined forgiveness as a form of transformation whereby a person's motivation to seek revenge and avoid an offending relationship partner diminishes and one's motivation to pursue conciliatory courses of action and goodwill for the offender increases. They posited that the most proximal or strongest determinants of forgiveness are the social-cognitive or affective variables such as empathy, rumination, and attribution. Empathy was found to be an important predictor of forgiveness with effect sizes $\left(r^{2}\right.$ values) ranging from $14 \%$ to $64 \%$ (McCullough, Fincham, \& Tsang, 2003; Welton et al., 2008).

Table 1

Summary Table of Determinants of Forgiveness by McCullough et al. (1998)

\begin{tabular}{llll}
\hline Social-Cognitive & Offense-Related & Relationship-Specific & Personal Influences \\
\hline Empathy & Severity & Quality of Relationship & Personality \\
Rumination & Apology & & Religion \\
Attribution & & & \\
\hline
\end{tabular}

The next proximal set of variables is the offense-related determinant such as perceived severity of the offense and the extent to which an offender apologizes for the offense. A moderately distal set of determinants in forgiveness involves relationship-specific variables that include commitment or quality of the relationship with the offender. The most distal determinants of forgiveness are the personal influences including personality and religion.

Tripartite forgiveness typology - A meta-analytic study on correlates of interpersonal forgiveness by Fehr et al. (2010) proposed a tripartite forgiveness typology. They argued that an offended person's prosocial motivational transformation occurs via three correlates of forgiveness: (a) cognitions, (b) affect, and (c) constraints. These correlates are differentiated into situational or context of the offenses versus dispositional or stable individual differences (see Table 2).

The first correlate is mitigating cognitions about the offense and the offender. Forgiving an offender involves making sense of the offense. The offended person evaluates the severity of the harm done and may ruminate over it. As the offended person seeks to understand what happened, the offender's intent and responsibility, and the presence and absence of apology may influence the willingness to forgive. Also, the offended person's cognitive dispositions such as agreeableness, perspective taking, and trait forgiveness predispose the person's particular interpretations of conflicts in general which may enhance or hinder forgiveness. 
The second correlate of forgiveness is the affect. As the person undergoes the process of forgiveness, negative mood or strong feelings (affect) may emerge such as anger towards the offender. The negative emotional experience is attributed to the offender and so decreases the likelihood of the offended person to forgive. On the contrary, positive emotional experience such as empathy toward the offender facilitates forgiveness. Moreover, the person's dispositional tendencies to experience certain moods and emotions such as trait anger, empathic concern are associated with forgiveness.

The third correlate of forgiveness is the relational or social-moral constraints on forgiveness. Relationship closeness, satisfaction, and commitment play a role in one's decision to forgive. A person who has been offended considers the implications of not forgiving the offender. People who are in close and satisfying relationships are likely to be committed to each other especially in restoring the relationship. If the relationship is destroyed by the offense, both parties might suffer a significant loss. Anticipating such loss might lead the offended person to consider forgiveness as a way of saving the relationship.

Also, internalized socio-moral expectations such as religiosity and social desirability are associated with forgiveness. One's religion may exert social pressure on the self to act in a socially desirable manner. According to Fehr et al. (2010), to forgive is considered a socially desirable response to an interpersonal offense.

Table 2

Summary Table of the Tripartite Forgiveness Typology

\begin{tabular}{lll}
\hline Factors & Situational Correlates & Dispositional Correlates \\
\hline Cognitions & Intent & Agreeableness \\
What happened? & Responsibility & Perspective-taking \\
& Apology & \\
& Harm Severity forgiveness \\
& Rumination & \\
Affect & Positive mood & Neuroticism \\
How do I feel? & Negative mood & Trait anger \\
& State empathy & Empathic concern \\
& State anger & Self-esteem \\
Constraints & Depression \\
What if I do not forgive? & Relationship closeness & Religiosity \\
& Relationship commitment & Social Desirability \\
\hline
\end{tabular}

\subsection{Conceptual Framework}

Two foundational concepts in Filipino culture according to Reyes (2015) are the basis of Filipino relationships. The first concept is loob (literally means inside) which he translated as 'relational will.' He referred loob to both the core of personhood and core that is in the relationship. Loob is always examined within the context of a relationship. The second concept is kapwa (literally means as other person) which according to Reyes (2015), is better understood as 'together with the person'. Relating to the social-cognitive and affective determinants of forgiveness by McCullough et al. (1998) and Fehr et al. (2010), Filipino's concept of loob refers to thoughts and emotions about the interpersonal offense. Contributing factors in forgiving include cognitive-based factors such as contemplating and reflection on the offense (Runguin \& Rungduin, 2013), and the depth of the impact of the negative experience associated with it (Lozada, Macatangay, \& Rufino, 1999).

Moreover, similar to the relational determinants such as closeness, satisfaction and commitment by McCullough et al. (1998) and Fehr et al. (2010), Filipinos' concept of kapwa gives importance on maintaining harmony and smooth interpersonal relationships with the other person. These two concepts, loob and kapwa are found in Filipino qualities such as pakikiramdam (relational sensitivity), kagandahang-loob (affective concern for others), and utang na loob (sense of indebtedness), which aim to preserve and strengthen human relationships (Reyes, 2015). 
Empathy in the frameworks of McCullough et al. (1998) and Fehr et al. (2010) was also found to be highly evident in Filipino forgiveness studies (Rungduin \& Rungduin, 2013). Empathy is commonly defined as putting oneself in someone else's situation to understand the other person's feelings and experiences. In a study by Rungduin and Rungduin (2013), they extracted Filipino values that emerged in the process of forgiveness. They suggested that empathy could be equivalent to pakikiramdam, a Filipino interpersonal value. Pakikiramdam or relational sensitivity is about being skilled in reading the other person's feelings and correctly guessing his/her inner state (Reyes, 2015). It involves being sensitive to subtle facial expressions, the tone of voice and bodily gestures, and other indirect forms of communication. According to Reyes (2015), this becomes a way of evaluating and deepening the relationship with the other person. But empathy in relation to forgiveness seems to be more than pakikiramdam or being sensitive in determining what the other person feels. Empathy among Filipinos also involves an affective response towards the emotional experience of another person. Empathy, in this case, is translated as pakikiisang loob among Filipinos (Tanalega \& Gonzales, 1989).

A person with pakikiisang loob (unity of will or being one with the other person) allows the self to enter the world of another person, ride on the other's experience and feel what the other person feels and treats them as one's own. The other person is viewed as a human being with fears, vulnerability, and a capability to make mistakes. In this study, empathy is regarded as both pakikiramdam and pakikiisang loob. Empathy enables the offended person to view the offender as a person of worth and thus deserves to be forgiven. According to Worthington (1998), empathy mediates forgiveness, which means that without empathy, a person is unlikely to forgive. Without the ability to recognize and understand the emotional needs in others, caring and compassion becomes thwarted (Hill, 2010). Furthermore, similar to relational determinants of McCullough et al. (1998), and Fehr et al. (2010), pakikisama or accommodative value was also found to be evident in forgiving others. Pakikisama strengthens the likelihood of granting forgiveness due to the feeling of being obligated to do it (Rungduin \& Rungduin, 2013).

In relation to Filipino's accommodative value, a person's utang na loob or sense of indebtedness is a response to other person's kagandahang loob or affective concern (Reyes, 2015). Utang na loob is not in the models of McCullough et al. (1998) and Fehr et al. (2010). However, it is included in this study because it is an important Filipino value and is very common in Filipino relationships. A person with utang na loob imposes on the self to return the same kind of kagandahang loob or affective concern shown by someone else. If a person returns the favor that is more than what is due, then the other person now becomes the one with utang na loob. According to Reyes (2015), this becomes a circular dynamic that continues to alternate and strengthen the relationship and inter-dependence in the process. This is where mutually sacrificial friendships develop. Utang $n a$ loob is personal and sympathetic in character. It is also free from external compulsion; it is self-imposed. To have utang na loob means that one values the other person and seeks to prolong and strengthen the relationships.

Finally, related to the personal influences determinant of McCullough et al. (1998) and dispositional correlates on constraints of Fehr et al. (2010), religiosity or spirituality is an important contributing factor of forgiveness among Filipinos in the cultural/social level (Rungduin \& Rungduin, 2013). Examination of the studies in the Philippines reveals that religiosity as the source of strength, relationship with the Supreme Being (Yabut, 2005), and spirituality (Galeon \& Tiu, 2003) facilitate forgiveness. It seems that among Filipinos, forgiveness involves reflection on the impact of the offense on the self $(l o o b)$ and a shift of focus from self to the offender and their relationship (kapwa). Spirituality or religiosity also appears to be an important aspect in forgiveness. Thus, relational determinant and constraint such as relational closeness, satisfaction, commitment, and religiosity or spirituality must be further explored in the framework since they seem to be important factors of forgiveness among Filipinos.

This study proposed an integrated model of forgiveness using the perspective of Markus and Kitayama (2010) in their study of culture and self. They proposed that self is defined as the "me" at the center of experience, which is indirectly and overtly at work in all aspects of behavior including attention, perception, cognition, emotion, motivation, relationships, and group processes. Every individual self carries elements of 
independent self and interdependent self in varying degrees. The primary referent of an independent schema of self in organizing behavior is the person's own thoughts, feelings, and actions (Markus \& Kitayama 1991). For an independent self, interaction with other people yields a sense of self as separate. On the other hand, the interdependent schema of self's primary referent in organizing behavior include the thoughts, feelings, and actions of others with whom the person is in a relationship with. For the interdependent self, interaction with others yields a sense of self as connected to or interdependent with others.

Using this perspective, a person who has been offended may focus on self (independent self) in dealing with own thoughts, emotions about the impact of the offense. This is similar to focus on loob. But also, that person focuses on the other or the offender and their relationship (interdependent self). This is similar to focus on kapwa. Incorporating the determinants of forgiveness in the framework of McCullough et al. (1998) and the tripartite typology of forgiveness by Fehr et al. (2010), the predictors in this study are categorized according to the following factors: (a) impact on self (offended person), (b) offender's behavior (after the offense), (c) relationship (before the offense), and (d) spirituality. The term spirituality will be used instead of religiosity so as not to limit the concept only to religious traditions, practices, and rituals. The integrated model of forgiveness is shown in Figure 1. Under each factor, there are correlates which have been discussed in the framework of McCullough et al. (1998) and Fehr et al. (2010) with another correlate added from Filipino forgiveness studies (see Table 3). The terminologies factor and correlates were obtained from the framework of Fehr et al. (2010).

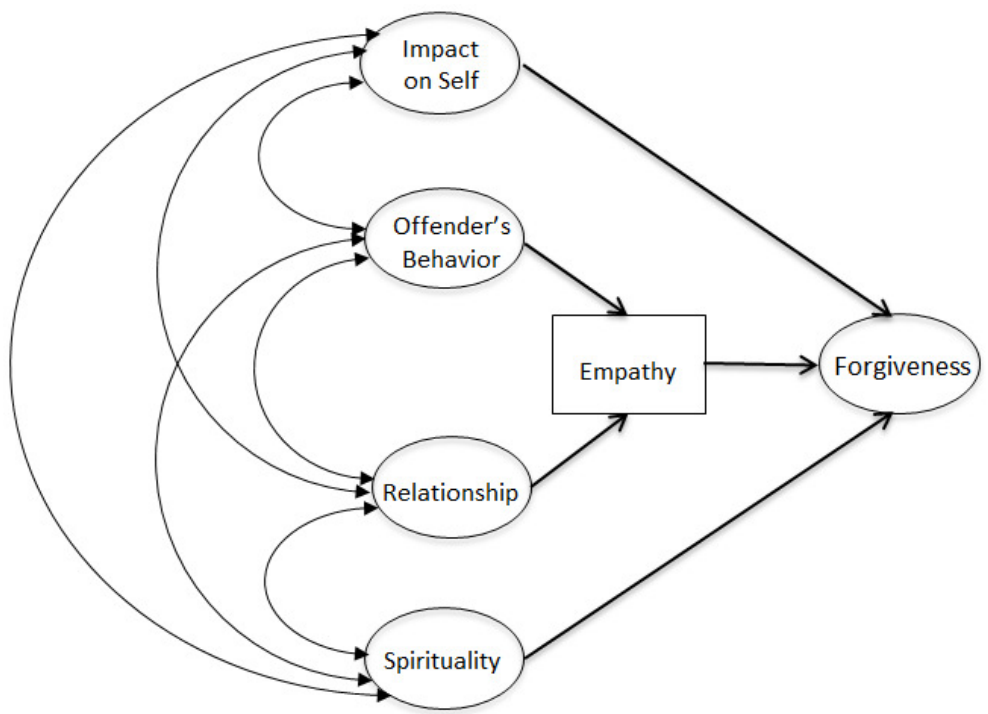

Figure 1. Hypothesized integrated model of forgiveness in personal relationships

Table 3

Factors and Correlates of Integrated Model of Forgiveness in Personal Relationships

\begin{tabular}{ll}
\hline Factors & Correlates \\
\hline Forgiveness & Non-avoidance \\
& Absence of Revenge \\
& Benevolence \\
& Perceived Severity \\
Impact on Self & Negative Emotions \\
& Rumination \\
& Attribution \\
& Acknowledging the Offense \\
Offender's Behavior & Making amends \\
& Quality of Relationship \\
Relationship & Commitment \\
& Sense of Indebtedness (Utang na Loob) \\
& Spiritual Appraisal of the Relationship of the Self with God \\
Spirituality & Spiritual Appraisal of the Offense \\
\hline
\end{tabular}




\subsection{Hypotheses}

This study aims to test the proposed Integrated Model of Forgiveness in Personal Relationships. In doing so, the following hypotheses are tested:

\section{Forgiveness is influenced by:}

$>$ Empathy toward offender

$>\quad$ Impact on self (perceived severity, negative emotions, rumination, and attribution)

$>$ Spirituality (spiritual appraisal of the relationship of the person offended with God, spiritual appraisal of the offense).

\section{Empathy, in turn, is influenced by}

$>\quad$ Offender's behavior after the offense (acknowledgment of the offense and making amends)

$>\quad$ Relationship (quality of relationship, commitment, and sense of indebtedness or utang na loob).

All factors (impact on self, offender's behavior, relationship, and spirituality) are significantly correlated with each other.

\section{Method}

This study used a survey design with late adolescents who experienced interpersonal offenses committed by loved ones such as family members, close friends or significant others. This study used a quantitative approach and the data obtained were analyzed using structural equation modeling (SEM).

\subsection{Participants}

One thousand and two hundred (1200) college students from eight universities and colleges (7 private and 1 state university) in Metro Manila agreed to complete a questionnaire. The research coordinator or administrator of each college/university selected the participants in the research. The age range of the students is between 16 and 22 years old $(M=18.16$ years, $S D=1.40)$. Sixty-five percent of the participants are females. Majority of the participants $(81.8 \%)$ are Roman Catholics, $8.8 \%$ are Christians, while the rest $(9.4 \%)$ belong to other denominations (e.g., Iglesia Ni Kristo, Jehovah's Witness, Buddhism, Islam, and others).

\subsection{Measures}

A survey packet consisting of an informed consent form and a series of questionnaires measuring the factors and correlates of forgiveness were administered to the participants. The items are rated using a 5-point Likert Scale $(1-$ strongly agree to 5 - strongly disagree). The first part of the questionnaire asks the participant to think about a loved one who had offended him/her in the past and to briefly describe the offense.

Forgiveness - Forgiveness pertains to the motivations to forgive the offender on three dimensions: non-avoidance, absence of revenge and benevolence towards the offender. It is measured by 18 items of Transgression-Related Interpersonal Motivations Inventory (TRIM-18, McCullough \& Hoyt, 2002). Previous studies have shown that avoidance and revenge subscales have high internal consistency $(\alpha=.85)$, moderate test-retest reliability and construct validity; while benevolence subscale showed good reliability (McCullough, Root, \& Cohen, 2006). In this study, the items for avoidance and revenge in TRIM-18 were reversely scored. High score means less likelihood to avoid the offender and take revenge and high likelihood to be benevolent toward the transgressor. Items on non-avoidance (Cronbach's $\alpha=.94$ ), absence of revenge (Cronbach's $\alpha=.88$ ) and benevolence (Cronbach's $\alpha=.90$ ) were found to be reliable.

Empathy - Empathy pertains to emotional identification toward another person a certain time. It was measured by eight items taken from the 8-item Batson Empathy Adjectives (McCullough et al., 1998; Davis, 
Worthington, Hook, \& Hill, 2013). This scale shows evidence of construct validity and was found to be positively correlated with measures of trait empathy such as empathic concern and perspective taking, and helping behavior. Internal reliability for this scale ranges from .79 to .95 (Davis et al., 2013). The instruction for this test was revised to assess empathy in the context of the offense. The respondent was asked how he or she feels about the offender after the offense. In this study, items on empathy were found to be reliable with Cronbach's $\alpha=.93$.

Impact on self - Impact on self pertains to thoughts, emotions, perceptions and attributions made about the offense. As the person suffers the consequences of the offense, the person may experience negative emotions and ruminate about the offense before going through the decision to forgive and let go. Perceived severity of the offense pertains to the gravity or harshness of the offense as perceived by the victim. It was measured by four items designed by the researcher. These items were found to be reliable with Cronbach's $\alpha=.82$. Negative emotions pertain to emotional experiences related to the offense. Negative emotions were measured using five items scale designed by the researcher. These items were found to be reliable with Cronbach's $\alpha=.91$. Rumination is defined as negative recurrent thoughts about the offense. It was measured by seven items adapted from the rumination dimension of the Rumination-Reflection Questionnaire (Trapnell \& Campbell, 1999). The items were revised to assess rumination in the context of the offense. The revised items were found to be reliable with Cronbach's $\alpha=.93$. While, Attribution is defined as the offended person's perception of the cause of the offense related to the responsibility and intentionality of the offender. It was measured by five items adapted from Causal Dimension Scale for Close Relationship (CDCR, Grunau, 1988). The items in CDCR were revised to assess perceptions of causal attributions in the context of the offense. The revised items were found to be reliable with Cronbach's $\alpha=.86$.

Offender's behavior - Offender's behavior pertains to the efforts by the offender to apologize after the offense. It is the degree to which the offender acknowledged his or her fault, expressed remorse and made amends as perceived by the person who was hurt. Acknowledging the offense involves the offender admitting the offense and expressing remorse towards the person offended. It was measured by two self-made items which were found to be reliable with Cronbach's $\alpha=.82$. While, Making amends involves the offender's efforts to show concern and to improve behavior towards the person offended. It is measured by three self-made items which were found to be reliable with Cronbach's $\alpha=.90$.

Relationship - Relationship involves the person's perception of the quality of relationship, level of commitment in the relationship and sense of indebtedness (utang na loob) towards the offender prior to the offense. Quality of relationship pertains to a close and satisfying relationship with the offender before the offense. It involves a person's perceptions of time invested, interconnected identity, memories and shared experience in the relationship with the offender. It also includes the degree of satisfaction the person has experienced in terms of fulfilled needs for intimacy, companionship, security and emotional involvement in the relationship. It was measured using eight items adapted from Investment and Satisfaction Dimensions of the Investment Model Scale by Rusbult, Martz, and Agnew (1998). The items were revised to assess the quality of relationship in the context of the offense. The revised items were found to be reliable with Cronbach's $\alpha=.93$. Commitment pertains to the degree to which one intends to persist in the relationship with the other. It was measured by two items taken from Commitment Dimension of the Investment Model Scale by Rusbult et al. (1998). The items were revised to assess the level of commitment in the context of the offense. The two revised items were found to be reliable with Cronbach's $\alpha=.84$. While, Sense of indebtedness (utang na loob) is the degree to which the person offended feels obligated to return the favor or kindness shown by the offender before the offense. It was measured by four self-made items which were found to be reliable with Cronbach's $\alpha=.88$.

Spirituality - It pertains to a person's spiritual appraisal of the relationship of self with God and spiritual appraisal of the offense or finding higher meaning in the offense. Spiritual appraisal of the relationship of self with God pertains to seeking help of the Higher Being in dealing with the offense. This correlate was measured using three items adapted from Brief Multidimensional Measurement of Religiousness/Spirituality (BMMRS, 
Fetzer Institute, National Institute on Aging Working Group, 1999). The items were revised to assess spirituality in the context of the offense. The revised items were found to be reliable with Cronbach's $\alpha=.94$. While, Spiritual appraisal of the offense pertains to viewing an offense as having spiritual meaning. This correlate was measured by three items taken from BMMRS (Fetzer Institute, NIA, 1999). Items were revised to assess spirituality in the context of the offense. The revised items were found to be reliable with Cronbach's $\alpha=.93$.

\subsection{Procedure}

The researcher first sought the approval of the director for research or administrator of eight selected universities and colleges ( 7 private and 1 state university) in Metro Manila to administer the survey questionnaire to their students who are between 16 and 22 years old. This was to ensure that the research protocol and survey questionnaire were properly reviewed for ethical considerations and to guarantee protection of the research participants from physical or psychological harm. The research director or administrator of the university/college then assigned the students who were available to participate in the study. The researcher administered the survey during their free time. In the event that the researcher could not administer the survey personally to the students, the counselor or college instructor of the school was authorized by the administrator to administer the survey to the selected classes. These counselors and college instructors were briefed about the instructions in administering the survey.

Participants were then oriented about the purpose of the study. An informed consent form was read to them which stated that there are no serious risks that will result from their participation in the study and that their identity and test results will not be revealed in any publication resulting from the study. The informed consent also stated that their participation is voluntary and they are free to choose whether to give their consent to participate in the study or not.

\subsection{Data Analysis}

Pilot test among 134 college students was conducted to initially examine the validity and reliability of the measures. Principal components analysis (PCA) with oblique rotation using SPSS was used in a first order analysis to examine the validity of measures of the correlates. Separate analyses were conducted for each factor in the hypothesized model. Items that did not load with the intended measures of a correlate, or items that loaded on two correlates were eliminated from the analysis (Tabachnick \& Fidell, 2007). For poorly defined correlates, items were re-worked or new items were created. A second run was conducted. The subsequent data $(\mathrm{N}=1200)$ collected for the study were analyzed again.

As with the pilot test, first order analysis was conducted separately for each of the factors to establish construct validity. Thus, factor analysis was conducted for forgiveness which showed that the measures of the correlates non-avoidance ( 7 items), absence of revenge (5 items) and benevolence (6 items) loaded on three separate components as expected. First order analysis also showed that the measures of the correlates of impact on self: perceived severity (4 items), negative emotions (5 items), rumination ( 7 items) and attribution (5 items) formed four components. Measures of the correlates of offender's behavior: acknowledging the offense ( 2 items) and making amends (3 items) formed two components. Measures of the correlates of relationship: quality of relationship ( 8 items), commitment (2 items) and sense of indebtedness (4 items) loaded on three separate components. Measures of the correlates of spirituality: spiritual appraisal of the relationship of self with God (3 items) and spiritual appraisal of the offense ( 3 items) formed two components. The intended measures for each of the correlates converged together, forming components different from the other measures of other correlates, lending both convergent and discriminant validity for each of the correlates of the factors (Hair, Black, Babin, \& Anderson, 2010).

Having established the construct validity for measures of the correlates, inter-item reliability was obtained using Cronbach's alpha. Cronbach's alpha for all of the correlates were all above 0.7 indicating that the measures 
for each construct was reliable, apart from also having construct validity. Composite scores for each of the correlates were then obtained. These mean scores were used as measures of the correlates which were indicators of the factors in the hypothesized model.

To examine the hypothesized model, structural equation modeling (SEM) was used. Structural equation models integrate multiple independent variables, dependent variables and hypothetical latent construct that clusters of observed variables might represent. It also allows researchers to test set of relationships among observed and latent variables as a whole and allow theory testing even when experiments are not possible (Savalei \& Bentler, 2006). In SEM, two parts of the hypothesized model are simultaneously tested: SEM confirms that the correlates are indicators of each factor (measurement model), and it also tests the predictive paths from one factor to another (path model). EQS 2.1 program was used, with Maximum Likelihood (ML) and robust method which accommodates nonnormal distributions.

\section{Results and Discussion}

The first part of the questionnaire asked the participants to think of a person (a family member, friend or a significant other) who offended them at some point in their life. They were also asked to briefly describe the offense, when it happened and how often they see or interact with the offender. Almost half of the participants $(47.6 \%)$ indicated that a friend was the offender. The rest of the participants indicated that the offender was a romantic partner $(22.9 \%)$, a family member $(22.6 \%)$, others $(6.9 \%)$ such as their professor or neighbor. The participants indicated that the offense happened recently or within a year ago $(49.50 \%)$, two to five years ago $(30.75 \%)$, more than five years ago $(6.42 \%)$, and a few stated it happens always or everyday (3.58 \%). The rest $(9.75 \%)$ did not indicate their answers.

Table 4 shows the offenses experienced by the participants. The offenses were grouped together into six categories. Majority of the participants indicated that they experienced offenses involving aggressive or inconsiderate behaviors $(31.67 \%)$, offenses related to trust issues $(27.5 \%)$, rejection $(17.58 \%)$, or other offenses such as family-related issues, selfishness, and misunderstanding (14.08\%). In terms of the frequency of interaction with the offender, the participants indicated that they see the offender always or everyday $(22.42 \%)$, not anymore $(19.17 \%)$, occasionally or sometimes $(15.42 \%)$, rarely $(14.17 \%)$, and often $(9.42 \%)$. The rest $(19.42 \%)$ did not indicate their answers.

\section{Table 4}

Percentage Distribution of Participants According to Offenses Experienced

\begin{tabular}{lc}
\multicolumn{1}{c}{ Offenses } & $\%$ \\
\hline $\begin{array}{l}\text { Aggressive behavior/Inconsiderate behavior (abuse, bullying, saying offensive words, rude } \\
\text { behavior, physical injury, being judged, humiliation, manipulation, stealing, being }\end{array}$ & 31.67 \\
$\begin{array}{l}\text { irresponsible, ruin reputation, disrespect, inflicting emotional pain) } \\
\text { Trust Issues (betrayal, cheating, lying/dishonesty, backstabbing, gossip) }\end{array}$ & \\
$\begin{array}{l}\text { Rejection (abandonment, taken for granted, avoiding/keeping distance, break up, devaluation, } \\
\text { discouragement, discrimination) }\end{array}$ & 27.50 \\
$\begin{array}{l}\text { Misunderstanding (quarrel, disagreement, blaming) } \\
\text { Selfishness (unfair treatment, unfulfilled promises, being used) }\end{array}$ & 17.58 \\
Family issues (dispute among family members, sibling rivalry, no financial support, threats & 5.58 \\
to family relationships) & 2.25 \\
Others (deliberate neglect of duties, unfulfilled promises, carelessness) & 1.42 \\
No answer & 4.83 \\
& \multicolumn{1}{c}{ Total } \\
\hline
\end{tabular}

\subsection{Descriptive Statistics}

Table 5 shows the descriptives and Cronbach alpha for each factor and correlate. Participants showed high mean score in the spirituality factor specifically in spiritual appraisal of the relationship of self with God 
What does it take to forgive? Predictors of forgiveness among Filipino late adolescents

correlate. The scores under spirituality, however, were negatively skewed. Transformation of scores in spirituality was done to correct the negatively skewed data (Field, 2005) prior to analysis using SEM. Participants also scored high in absence of revenge and quality of relationship. Participants have low mean scores in making amends and attribution. The participants' scores in commitment have the highest variability among the other correlates. Correlates of forgiveness and relationship, negative emotions and making amends have nonnormal distribution.

Table 5

Descriptive Statistics of Factors \& Correlates of the Integrated Model of Forgiveness in Personal Relationships

\begin{tabular}{|c|c|c|c|c|c|}
\hline Factors and Correlates & $\begin{array}{l}\text { No. of } \\
\text { items }\end{array}$ & $\mathrm{M}(\mathrm{SD})$ & Skewness & Kurtosis & $\begin{array}{c}\text { Cronbach's } \\
\text { Alpha }\end{array}$ \\
\hline \multicolumn{6}{|l|}{ Forgiveness } \\
\hline Non-Avoidance & 7 & $3.17(1.15)$ & -.20 & -.87 & .94 \\
\hline Absence of Revenge & 5 & $3.86(.99)$ & -.87 & .26 & .88 \\
\hline Benevolence & 6 & $3.41(.99)$ & -.31 & -.41 & .90 \\
\hline Total & 18 & $3.49(.79)$ & -.17 & -.27 & \\
\hline Empathy & & $2.96(.88)$ & -.11 & -.11 & .93 \\
\hline \multicolumn{6}{|l|}{ Impact on Self } \\
\hline Perceived Severity & 4 & $3.26(.97)$ & -.07 & -.65 & .82 \\
\hline Negative Emotions & 5 & $2.93(1.08)$ & .16 & -.64 & .91 \\
\hline Rumination & 7 & $3.03(.97)$ & .05 & .56 & .93 \\
\hline Attribution & 5 & $2.90(.87)$ & .14 & -.11 & .86 \\
\hline Total & 21 & $3.03(.77)$ & .08 & -.38 & \\
\hline \multicolumn{6}{|l|}{ Offender's Behavior } \\
\hline Acknowledging the Offense & 2 & $2.93(1.10)$ & .02 & -.73 & .82 \\
\hline Making Amends & 3 & $2.76(1.14)$ & .18 & -.82 & .90 \\
\hline Total & 5 & $2.84(1.00)$ & .09 & -.58 & \\
\hline \multicolumn{6}{|l|}{ Relationship } \\
\hline Quality of Relationship & 8 & $3.57(.98)$ & -.67 & -.12 & .93 \\
\hline Commitment & 2 & $3.54(1.17)$ & -.52 & -.63 & .84 \\
\hline Sense of Indebtedness & 4 & $3.37(1.00)$ & -.39 & -.43 & .88 \\
\hline Total & 14 & $3.49(.93)$ & -.61 & -.20 & \\
\hline \multicolumn{6}{|l|}{ Spirituality } \\
\hline Relationship of Self with God & 3 & $4.32(.86)$ & -1.51 & 2.35 & .94 \\
\hline Spiritual Appraisal of the offense & 3 & $4.26(.85)$ & -1.24 & 1.44 & .93 \\
\hline Total & 6 & $4.29(.82)$ & -1.40 & 2.11 & \\
\hline
\end{tabular}

Note. Standard Error of Skewness $=.07$ and Error of Kurtosis $=.141$

\subsection{Structural Equation Modeling}

Preliminary analyses were done to ensure that problems in the measurement model of SEM were minimized. Factor analysis of the correlates of the factors forgiveness, impact on self, offender's behavior, relationship, and spirituality formed components with items measuring each correlate converging together, forming components different from other correlates. A second order analysis with the composite scores of the correlates of each factor was also done using factor analysis. Benevolence loaded higher in relationship factor (loading of 0.32) than in forgiveness factor (loading of 0.23 , see Appendix A). Nevertheless, benevolence was still considered as a correlate of forgiveness factor according to the theory of McCullough et al. (1998).

The adequacy of the model was analyzed using SEM with the EQS program that allows robust methods that accommodate nonnormal distributions. The model was tested with standardized coefficients obtained from the Maximum Likelihood (ML) method of estimation. Three measures were used to evaluate goodness of fit of the model: (a) Chi-Square, (b) Comparative Fit index (CFI), and (c) Root Mean Square of Error of Approximation (RMSEA). To show a good fit for a model with more than 12 but less than 30 observed variables and a large sample size (more than 250 respondents), the following criteria must be met: probability value of chi-square is expected to be significant, CFI must be greater than 0.92 and RMSEA should be less than .07 (Hair et al., 2010). 
In the measurement model, all loadings were significant with values ranging from .42 to .99 (see Appendix B). Results, however, showed poor fit (see Appendix C). Satorra-Bentler Scaled Chi-Square of 665.34 with $p=$ 0.00 was significant, $\mathrm{CFI}=.91$ and RMSEA $=.08$, all of which did not meet the criteria for a good model. LaGrange Multiplier Test suggested that a path is added from relationship to benevolence. It seemed logical to add this path since people in high quality relationships characterized by high satisfaction, closeness, and commitment are more likely to forgive (Fehr et al., 2010; McCullough et al., 1998). They are willing to give up the hurt and release the anger brought by the offense to restore the relationship. After adding the path, results showed that Satorra-Bentler Scaled Chi-Square of 507.21 with $p=0.00$ was significant, but this is expected because of the large sample size (Hair et al., 2010.) The other two fit indices CFI $=.94$ and RMSEA $=.07$ suggested an adequate fit. All path coefficients in the measurement model were significant with values ranging from .23 to .99 (see Table 6), with benevolence loading on both forgiveness and relationship.

Table 6

Measurement Model of Modified Integrated Model of Forgiveness in Personal Relationships

\begin{tabular}{|c|c|c|c|c|c|c|}
\hline Correlates & Forgiveness & Self & $\begin{array}{c}\text { Offender's } \\
\text { Behavior }\end{array}$ & Relationship & Spirituality & $\mathrm{R}^{2}$ \\
\hline Non-Avoidance & $.85^{*}$ & & & & & .72 \\
\hline Absence of Revenge & $.60^{*}$ & & & & & .36 \\
\hline Benevolence & $.23^{*}$ & & & $.41 *$ & & .27 \\
\hline Perceived Severity & & $.62 *$ & & & & .38 \\
\hline Negative Emotions & & $.85^{*}$ & & & & .72 \\
\hline Rumination & & $.87 *$ & & & & .76 \\
\hline Attribution & & $.50 *$ & & & & .26 \\
\hline Acknowledging the Offense & & & $.61 *$ & & & .37 \\
\hline Making Amends & & & $.99 *$ & & & .98 \\
\hline Quality of Relationship & & & & $.77^{*}$ & & .60 \\
\hline Commitment & & & & $.85^{*}$ & & .72 \\
\hline Sense of Indebtedness & & & & $.83^{*}$ & & .68 \\
\hline Self and God & & & & & $.86^{*}$ & .75 \\
\hline Spiritual Appraisal of the Offense & & & & & $.94 *$ & .88 \\
\hline
\end{tabular}

Note. $* p<.05$

Figure 2 represents the standardized solutions for the structural model. All structural paths were found to be significant.

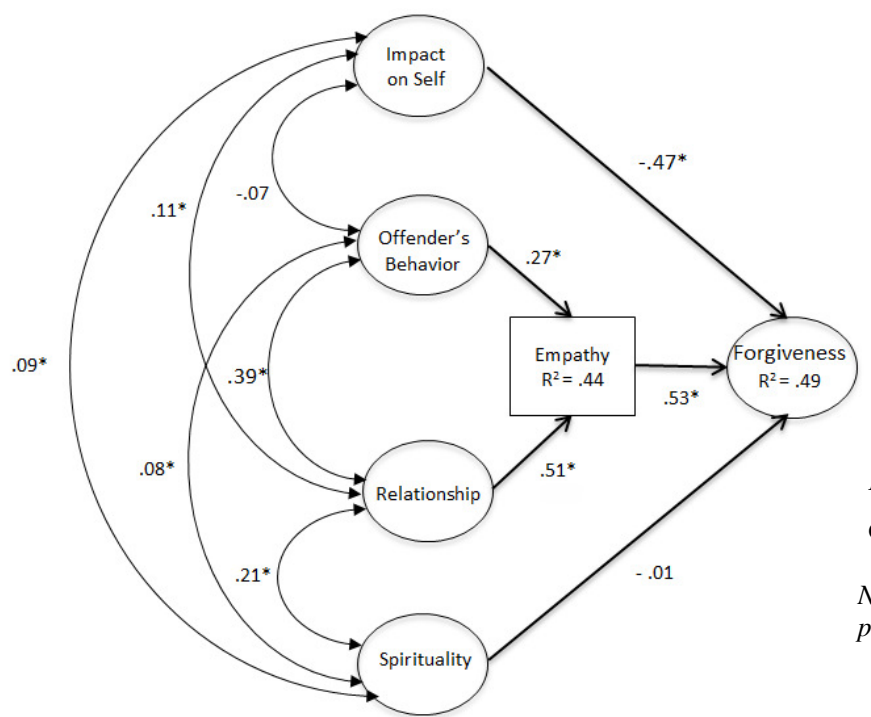

Figure 2. Modified integrated model of forgiveness in personal relationships

Note. Satorra-Bentler Scaled Chi-Square $=507.21$, $p<.05, \mathrm{CFI}=.94, \mathrm{RMSEA}=.07 * p<.05$

The integrated model showed that forgiveness was significantly predicted by empathy and impact on self, but not spirituality. Together, the predictors explain $49 \%$ of the variance in forgiveness. Empathy was further influenced by offender's behavior and relationship. The results did not support the hypothesis that forgiveness is 
significantly predicted by spirituality.

\subsection{Empathy, offender's behavior and relationship}

Empathy was the strongest predictor of forgiveness with $\beta=.53, p<.05$. This implies that when empathy is high, forgiveness is high. When an offended person makes an active effort to take the emotional perspective of the offender, the offended person is likely to forgive the offender. This is consistent with the findings of empathy as a crucial determinant of forgiveness (McCullough et al., 1997; McCullough et al., 1998; Welton et al., 2008; \& Rungduin \& Rungduin, 2013). Taking the emotional perspective of the offender and consequently feeling concerned, compassionate, moved and softhearted towards him or her increases the tendency to forgive. An offended person who shows empathy, is sensitive to the emotional experience of the offender (pakikiramdam) and treats this experience as if it was one's own (pakikiisang loob), regards the offender as a person of worth. The offender is viewed just like the self as a human being with vulnerabilities and is also capable of making mistakes. Such feelings of empathy involve a shift of focus from self to the other. This seems to help reduce feelings of estrangement and desire for revenge and to improve positive feelings and attitudes toward the offender. Among late adolescents, empathy facilitated adaptive behavior and reduces aggression and antisocial behaviors (LeSure-Lester, 2000). Empathy enables a prosocial change towards the offender which what happens in forgiveness (McCullough et al., 1998).

Empathy was significantly predicted by both offender's behavior $(\beta=.27, p<.05)$ and relationship $(\beta=.51$, $p<.05)$. Relationship is a better predictor of empathy as indicated by higher $\beta$ value. Together, the predictors explain $44 \%$ of the variance in Empathy. Benevolence, a correlate of forgiveness is also significantly predicted by relationship with $\beta=.41, p<.05$.

Empathy was significantly predicted by offender's behavior after the offense. Empathy for the offender seems to be higher when the offender acknowledges the offense and makes amends with the offended person. A person who apologizes admits faults; shows concern and remorse; tries to make up for the offense or improves behavior; and promises not to commit the offense again (Ebrada, 2004). The act of apologizing implies that the offender is bothered by conscience and has a desire to fix the relationship. It can communicate the guilt an offender feels which then could perhaps promote empathy (Riek \& Mania, 2012). Apologies contribute to the reparation of the offender's negative image in the eyes of the offended person (Hareli \& Eisikovits, 2006). The offended person who receives the apology recognizes the humanity of the offender who is capable of making mistakes and the humility it takes to apologize. The offended person then shows empathy by understanding the emotional perspective of the offender.

Empathy was significantly predicted by relationship before the offense. Empathy for the offender also seems to be higher when the relationship before the offense is considered of high quality, with high level of commitment and sense of indebtedness (utang na loob). This is consistent with the studies on marital and dating relationships (Fincham et al., 2002) and parent-adolescent relationships (Paleari, Regalia, \& Fincham, 2003), which showed that positive relationship quality promotes forgiveness via affective reactions and emotional empathy. According to Reyes (2015), the concept of kapwa enhances the feelings of empathy for the other. Among Filipino youth, the family and peer groups are major sources of affirmation and support (Puyat, 2005). They spend a considerable amount of time engaging in a lot of activities with people close to them especially with their peer group. Such closeness and commitment enables those in the relationship to have access to inner thoughts, feelings, and motivations of each other which may help them find more resources for experiencing empathy for each other (McCullough et al., 1998). Moreover, having a sense of indebtedness which involves being reminded of the kindness and affective concern shown by the offender in the past may trigger feelings of empathy towards the offended person. Past actions of respect in the relationship may temper the judgment against the offender (Enright \& Fitzgibbons, 2000). The offended person is likely to view the offender as not totally bad and deserves to be forgiven. Empathy and sense of indebtedness (utang na loob) are aimed at preserving and strengthening human relationships (Reyes, 2015). These qualities are present in forgiving others 
as evident in this study.

In addition, relationship has a direct link to benevolence, a correlate of forgiveness. This implies that even without empathy, an offended person, who has high quality relationship, high level of commitment and a sense indebtedness before the offense, is likely to regard the offender with benevolence. Quality of relationship, level of commitment, and sense of indebtedness motivate the offended person to move forward with the relationship despite the offense. Consistent with Fehr et al. (2010) and McCullough et al. (1998), people who are in high quality relationships characterized by high satisfaction, closeness, and commitment are more likely to forgive. The offended person is willing to release the anger, give up the resentment to restore the relationship.

\subsection{Impact on self}

Forgiveness was significantly predicted by impact on self $(\beta=-.47, p<.05)$, with negative direction and moderate strength. This means that if the offended person perceives the offense as severe, intentional, ruminates about it, and experiences negative emotions, then the person offended is unlikely to forgive. Interpersonal offenses disturb the core of personhood or loob of a person. The view of oneself is affected especially if the offense is perceived to be severe and intentional. An offended person is likely to ruminate about it and experience strong negative emotions such as anger, bitterness, and resentment. In this study, forgiveness is negatively predicted by the impact of the offense on self. This is consistent with the studies on the impact of severe offenses (McCullough et al., 1998; Fincham et al., 2005), negative-offender directed emotions (Fehr et al., 2010; Riek \& Mania, 2012), rumination (McCullough, Bono, \& Root, 2007; Wade et al., 2008), and attribution (Fincham et al., 2002; Paleari et al., 2003) on forgiveness. Previous studies suggest that college students are generally more deeply affected when severely hurt as shown by their low forgiveness and high anxiety levels (Subkoviak et al., 1995). One possible reason is that late adolescence is characterized by increases in internalizing and externalizing problems and negative emotions (Coban, 2013; Hawk et al., 2013). Ruminating about the offenses such as aggressive and inconsiderate behavior, betrayal, rejection experienced in friendships, family, and romantic relationships is common in late adolescents since interpersonal conflicts increase during this developmental period. Offenses that are severe and those that are perceived as intentional and under the control of the offender fuel ruminative thoughts and negative emotions. Their responses to such offenses are likely to avoid contact with and retaliate against the offender to protect themselves (McCullough et al., 1997).

\subsection{Spirituality}

Spirituality did not significantly predict forgiveness in the model. $(\beta=-.01, p>.05)$. Specifically, spiritual appraisal of the relationship of the offended person with God and spiritual appraisal of the offense did not have a significant influence on forgiveness. This is inconsistent with the studies which found a positive relationship between spirituality/religiosity and forgiveness (Fehr et al., 2010; Riek \& Mania, 2012; Touissant, Marschall, \& Williams, 2012). However, in the meta-analysis of Fehr and colleagues (2010), they found that religiosity accounted for only $3.6 \%$ of the variance in forgiveness which was interpreted as small in accordance with Cohen's (1988 as cited in Fehr et al., 2010) recommended cut-off. Furthermore, Subkoviak et al. (1995) showed that there was no general relationship between forgiveness and depth of religiosity. Religiosity was only significantly correlated with forgiveness when the person was hurt by a more distant person other than family member or friend. One possible explanation for this is that the influence of spirituality/religiosity appears to be under control of many proximal social-psychological conditions (McCullough \& Worthington, 1999). Spirituality/religiosity might be far back in the causal chain of forgiveness. Many studies showed that a person's forgiveness of a specific person for a specific transgression is influenced by a variety of social and social-cognitive factors (McCullough \& Worthington, 1999). In the model wherein the predictors of forgiveness were simultaneously analyzed, offender's behavior and relationship variables as mediated by empathy and impact on self appear to be the more important predictors of forgiveness than spirituality. Spirituality may have reduced impact on forgiveness when the offended person focuses on the impact of the offense on the self and the relationship with the offender. 
Another possible explanation for the non-significant findings between spirituality and forgiveness is the homogeneity of the samples in spirituality factor. The participants' mean score in spirituality is high, had low standard deviation and is negatively skewed. Perhaps the participants' positive responses in spirituality items such as 'my relationship with God helps me find purpose about the offense; the offense is part of the events in my life which unfolds according to a divine or greater plan,' reflect their tendency to put themselves in a favorable light. According to Fehr et al. (2010), a person's religion may exert social pressure on the self to act in a socially desirable manner.

\subsection{Correlations among factors of forgiveness}

Figure 2 also shows the correlations of the factors with each other. Though the correlations among factors, except for impact on self and offender's behavior, are significant, the correlations are weak. Offender's behavior was positively correlated with relationship with $r=.39, p<.05$. This implies that if the relationship before the offense was good, the offender is perceived to be more apologetic. In a high quality relationship, it is likely that the partners are committed to restoring the relationship. The offender is likely to acknowledge the offense and make amends to the offended person (Szablowinski, 2012). In turn, the offended person who is equally motivated to maintain the relationship and has a sense of indebtedness toward the offender will most likely acknowledge the offender's act of apologizing.

Though spirituality did not predict forgiveness, it was correlated with the perception of the relationship before the offense, $r=.21, p<.05$. This implies that if the relationship before the offense was good, spirituality is high. Spirituality plays a significant role among late adolescents. It affects an adolescent's overall sense of wellness (Spurr, Berry, \& Walker, 2013). Spirituality and religion are relevant to the development of interpersonal relationships. Religious attitudes and behaviors typically emerge in the context of significant, ongoing relationships (Baumbach et al., 2006).

\section{Limitations of the study and future directions}

This study contributes to the empirical findings of the factors associated with forgiveness. It simultaneously examined the relationships of the factors that predict forgiveness in one integrated model. The model showed the unique contribution of each factor to forgiveness among late adolescents. This study, however, has some limitations. First, this study used a survey design method. The results must be treated with caution. The study cannot establish causality because it is not experimental. However, given that the factors in the study are difficult to manipulate, the method employed in the study to test the model seemed to be appropriate in examining the possible cause and effect relationship of the factors. Secondly, the study focuses only on interpersonal forgiveness of a single offender by an offended person so the results are not applicable to multiple offenses or multiple offenders. Third, the study does not involve forgiveness of interpersonal offenses that may pose serious danger to the person such as those that involve physical, sexual abuse, assault or murder.

To obtain more comprehensive results, future research may also test the model to adults and elderly people. Testing the model to individuals from other regions aside from Metro Manila may also give a broader view about forgiveness among Filipinos. Since this study dealt with personal relationships in general, separate analyses of the model for romantic relationship, family relationship, and friendships may extend the findings of previous studies and meta-analyses on the determinants of forgiveness on which are the most important predictors of forgiveness among these kinds of relationships.

Majority of the measures used in this study were taken from western literature. Future research may attempt to indigenize the factors related to forgiveness most especially empathy since the findings of the study reveal that it is an important predictor of forgiveness. This can provide a better understanding of empathy as a Filipino construct. The indigenized items may directly elicit Filipino values of pakikiramdam (relational sensitivity) and pakikiisang loob (unity of will or being one with the other person) in the context of interpersonal offenses. 
According to Rungduin and Rungduin (2013), very few studies have investigated forgiveness behavior of Filipinos and how culture blend in this experience. Further examination of the relationship of empathy and forgiveness among Filipinos, incorporating the Filipino values and culture may contribute to the deeper understanding of how Filipinos forgive.

\section{Implications of the study and conclusion}

Despite the limitations, the practical implications of the study are worth mentioning. Late adolescents who have been offended by a loved one, a family member, a relative, a friend or romantic partner may benefit from this study by gaining a better understanding of what will help them forgive the offender and what keeps them from forgiving. One notable contribution of this study is its implication to counseling and therapy. This study can assist helping professionals handling transgressed adolescents. By having sufficient knowledge and mastery of the factors that predict forgiveness, helping professionals can facilitate the forgiveness journey of transgressed individuals at the most un-delayed time frame.

For instance, in helping an adolescent deal with an interpersonal offense by a very close friend, the counselor first allows the offended adolescent to focus on the impact of the offense on the self. The negative consequences of the interpersonal offense on the core of the person must be dealt with immediately to help reduce the offended person's motivation to avoid and take revenge and increase positive attitudes towards the offender. The counselor then gradually assists the offended adolescent to shift the focus from the self to the offender, helping the offended adolescent to understand and make sense of the offender's behavior.

Since empathy was found to be the most significant predictor of forgiveness, exercises in developing empathy may be helpful in seeing the offender as a person of worth and deserving of forgiveness. One technique that can enhance empathy is reframing which involves rethinking of a situation or seeing it with fresh eyes (Enright \& Fitzgibbons, 2000). Reframing is based on the assumption that cognitive insight on the emotional experience of the offender usually comes before positive affective responses towards an offender. Helping the offended person make sense of the offender's confusion, vulnerabilities and fears may lead to feelings of empathy and compassion.

To develop empathy even further, the counselor may help the offended adolescent pay attention to the offender's behavior after the offense specifically his or her active efforts to apologize, acknowledge the offense and make amends. This may arouse offended adolescent's positive affective response towards the offender's feelings of guilt and remorse.

Adolescents have a strong attachment to peer group (Coban, 2013) and are expected to maintain a healthy relationship with parents and peers (Cabigon, 1999). It may be helpful that forgiveness interventions tap their thoughts, feelings about the relationship with the offender, highlighting the quality of the relationship and the affective concern shown by the offender prior to the offense. In the given example, the offended adolescents may be reminded of the shared joys and closeness as friends. This may help reduce the ill thoughts and feelings towards the offender.

The interpersonal motivation to preserve and strengthen the relationship facilitates the development of empathy which thereby facilitates forgiveness. Strengthening the sense of togetherness with another person (kapwa) through empathy (pakikiramdam and pakikiisang loob) may generate a sense of compassion which facilitate prosocial behavior towards the offender. As a consequence, the cohesion, harmony, and affection that was once present in a certain family unit or the fidelity that once characterized a bond of friendship but was torn apart by a particular offense, can now be restored through forgiveness.

In conclusion, the Integrated Model of Forgiveness in Personal Relationships shows that among late adolescents, forgiveness is influenced by impact on self and empathy with empathy being the most important predictor of forgiveness. Empathy is further influenced by offender's behavior after the offense and the two 
What does it take to forgive? Predictors of forgiveness among Filipino late adolescents

parties' relationship before the offense. This implies that the act of acknowledging the offense and making amends toward the offended person is likely to be granted forgiveness through empathy. Moreover, focusing on the relationship with the offender before the offense may help develop empathy towards the offender, thereby increasing the likelihood for forgiveness. Though spirituality did not predict forgiveness, it still played an important role in the model because it is correlated with perception of relationship before the offense.

Overall, the results of this study imply that empathy should be strongly encouraged among Filipino late adolescents to facilitate forgiveness. Focusing on the offender's act of apologizing and relationship before the offense is one way to further promote empathy.

\section{References}

Baumbach, K., Forward, G. L., \& Hart, D. (2006). Communication and parental influence on late adolescent spirituality. Journal of Communication and Religion, 29(2), 394-420.

Cabigon, J. V. (1999). Understanding Filipino adolescents: Research gaps and challenges. Philippine Social Science Review, 56, 107-129.

Coban, E. A. (2013). Interpersonal cognitive distortions and stress coping strategies of late adolescents. Eurasian Journal of Educational Research, 51, 65-84.

Davis, D. E., Worthington, E. L., Hook, J. N., \& Hill, P. C. (2013). Research on religion/spirituality and forgiveness: A meta-analytic review. Psychology of Religion and Spirituality, 5(4), 233-241. https://doi.org/10.1037/a0033637

De Leon, M. L. (2008). Forgiveness therapy on transgressed college students from dysfunctional families: A multiple case study approach (Unpublished masteral thesis). University of Santo Tomas Graduate School, Manila, Philippines.

Ebrada, S. C. (2004). Sori, ha? Isang sikolohikal na pag-aaral sa personal na paghingi ng patawad [I'm sorry? A psychological study on personal apology] (Unpublished doctoral dissertation). Ateneo de Manila University, Manila, Philippines.

Enright, R. D. (2001). Forgiveness is a choice. Washington, D.C.: APA Life Tools.

Enright, R. D., \& Fitzgibbons, R. P. (2000). Helping clients forgive. Washington, DC: American Psychological Association.

Fehr, R., Gelfand, M. J., \& Nag, M. (2010). The road to forgiveness: A meta-analytic synthesis of its situational and dispositional correlates. Psychological Bulletin, 136(5), 894-914. https://doi.org/10.1037/a0019993

Fetzer Institute, National Institute on Aging Working Group. (1999). Multidimensional measure of religiousness, spirituality for use in health research: A report of a national working group. Retrieved from http://www.acperesearch.net/Fetzer_Book_extracts.pdf

Field, A. (2005). Discovering statistics using SPSS (2 ${ }^{\text {nd }}$ ed.). London: Sage Publications.

Fincham, F. D., Jackson, H., \& Beach, S. R. H. (2005). Transgression severity and forgiveness: Different moderators for objective and subjective severity. Journal of Social and Clinical Psychology, 24(6), 860-875. https://doi.org/10.1521/jscp.2005.24.6.860

Fincham, F. D., Paleari, F. G., \& Regalia, C. (2002). Forgiveness in marriage: The role of relationship quality, attributions and empathy. Personal Relationships, 9, 27-37. https://doi.org/10.1111/1475-6811.00002

Galeon, A., \& Tiu, A. (2003). Forgiveness: A tie that strengthens family relationships (Unpublished college thesis). De La Salle University, Manila, Philippines.

Grunau, G. (1988). Measuring attributions in close relationships: An extension of the causal dimension scale. Simon Fraser University. Retrieved from http://oatd.org/oatd/go?url=http\%3A\%2F\%2Fsummit.sfu.ca\%2Fitem\%2F5209\&from=record\&q=

Hair, J. F., Black, W. C., Babin B. J., \& Anderson, R E. (2010). Multivariate Data Analysis (7 ${ }^{\text {th }}$ ed.). New Jersey: Prentice Hall.

Hareli, S., \& Eisikovits, Z. (2006). The role of communicating social emotions accompanying apologies in forgiveness. Motivation and Emotions, 30, 189-197. https://doi.org/10.1007/s11031-006-9025-x 
De Leon, M. S. L., \& Lopez, G. D.

Hawk, S. T., Keijsers, L., Branje, S. J., Graaf, J. V., Wied, M. D., \& Meeus, W. (2013). Examining the interpersonal reactivity index (IRI) among early and late adolescents and their mothers. Journal of Personality Assessment, 95(1), 96-106. https://doi.org/10.1080/00223891.2012.696080

Hill, E. W. (2010). Discovering forgiveness through empathy: Implications for couple and family therapy. Journal of Family Therapy, 32(2), 169-185. https://doi.org/10.1111/j.1467-6427.2010.00492.x

LeSure-Lester, G. E. (2000). Relationship between empathy and aggression and behavior compliance among abused group home youth. Child Psychiatry and Human Development, 31(2), 153-161. https://doi.org/10.1023/A:1001900727156

Lozada, F., Macatangay, C., \& Rufino, R. (1999). The phenomenological analysis of the experience of forgiveness (Unpublished college thesis). De La Salle University, Manila, Philippines.

Markus, H. R., \& Kitayama, S. (1991). Culture and the self: Implications for cognition, emotion, and motivation. Psychological Review, 98(2), 224-253. https://doi.org/10.1037/0033-295X.98.2.224

Markus, H. R., \& Kitayama, S. (2010). Cultures and selves: A cycle of mutual constitution. Perspectives on Psychological Science, 5(4), 420-430. https://doi.org/10.1177/1745691610375557

McCullough, M. E., \& Hoyt, W. T. (2002). Transgression-related motivational dispositions: Personality substrates of forgiveness and their links to the big five. Personality and Social Psychology Bulletin, 28(11), 1556-1573. https://doi.org/10.1177/014616702237583

McCullough, M. E., \& Worthingon, E. L. (1999). Religion and forgiving personality. Journal of Personality, 67(6), 1142-1164. https://doi.org/10.1111/1467-6494.00085

McCullough, M. E., Bono, G., \& Root, L. M. (2007). Rumination, emotion, and forgiveness: Three longitudinal studies. Journal of Personality and Social Psychology, 92(3), 490-505. https://doi.org/10.1037/0022-3514.92.3.490

McCullough, M. E., Fincham, F. D., \& Tsang, J. A. (2003). Forgiveness, forbearance, and time: The temporal unfolding of transgression-related interpersonal motivations. Journal of Personality and Social Psychology, 84(3), 540-557. https://doi.org/10.1037/0022-3514.84.3.540

McCullough, M. E., Rachal, K. C., Sandage, S. J., Worthington, E. L., Brown, S. W., \& Hight, T. L. (1998). Interpersonal forgiving in close relationships II: Theoretical elaboration and measurement. Journal of Personality and Social Psychology, 75(6), 1586-1603. https://doi.org/10.1037/0022-3514.75.6.1586

McCullough, M. E., Root, L. M., \& Cohen, A. D. (2006). Writing about the personal benefits of a transgression facilitates forgiveness. Journal of Consulting and Clinical Psychology, 74(5), 887-897. https://doi.org/10.1037/0022-006X.74.5.887

McCullough, M. E., Worthington, E. L, \& Rachal, K. C. (1997). Interpersonal forgiving in close relationships. Journal of Personality and Social Psychology, 73(2), 321-336. https://doi.org/10.1037/0022-3514.73.2.321

Paleari, F. G., Regalia, C., \& Fincham, F. D. (2003). Adolescents' willingness to forgive their parents: An empirical model. Parenting: Science and Practice, 3(2), 155-174. https://doi.org/10.1207/S15327922PAR0302_03

Park, Y. O., \& Enright, R. D. (1997). The development of forgiveness in the context of adolescent friendship conflict in Korea. Journal of Adolescence, 20(4), 393-402. https://doi.org/10.1006/jado.1997.0095

Puyat, J. H. (2005). The Filipino youth today: Their strengths and the challenges they face. In F. Gale \& S. Fahey (Eds.), Youth in transition: The challenges of generational change in Asia (pp. 191-205). Retrieved from http://unesdoc.unesco.org/images/0014/001417/141774e.pdf

Reyes, J. (2015). Loob and kapwa: An introduction to a Filipino virtue ethics. Asian Philosophy, 25(2), 148-171. https://doi.org/10.1080/09552367.2015.1043173

Riek, B. M., \& Mania, E. W. (2012). The antecedents and consequences of interpersonal forgiveness: A meta-analytic review. Personal Relationships, 19(2), 304-325. https://doi.org/10.1111/j.1475-6811.2011.01363.x

Rungduin, D. C., \& Rungduin T. T. (2013). The emergence of Filipino values among forgiveness studies. International Journal of Research Studies in Psychology, 2(4), 17-34. https://doi.org/10.5861/ijrsp.2013.367 
What does it take to forgive? Predictors of forgiveness among Filipino late adolescents

Rusbult, C. E., Martz, J. M., \& Agnew, C. R. (1998). The investment model scale: Measuring commitment level, satisfaction level, quality of alternatives, and investment size. Personal Relationships, 5(4), 357-391. https://doi.org/10.1111/j.1475-6811.1998.tb00177.x

Savalei, V., \& Bentler, P. (2006). Structural equation modeling. The Handbook of Marketing Research, 330-364. https://doi.org/10.4135/9781412973380.n17

Seiffge-Krenke, I. (2011). Coping with relationship stressors: A decade review. Journal of Research on Adolescence, 21(1), 196-210. https://doi.org/10.1111/j.1532-7795.2010.00723.x

Spurr, S., Berry, L., \& Walker, K. (2013). The meanings older adolescents attach to spirituality. Journal for Specialists in Pediatric Nursing, 18(3), 221-232. https://doi.org/10.1111/jspn.12028

Struthers, C. W., Eaton, J., Santelli, A. G., Uchiyama, M., \& Shirvani, N. (2008). The effects of attributions of intent and apology on forgiveness: When saying sorry may not help the story. Journal of Experimental Social Psychology, 44, 983-992. https://doi.org/10.1016/j.jesp.2008.02.006

Subkoviak, M. J., Enright, R. D., Wu, C., Gassin, E. A., Freedman, S., Olson, L. M., \& Sarinopoulous, I. (1995). Measuring interpersonal forgiveness in late adolescence and middle adulthood. Journal of Adolescence, 18(6), 641-655. https://doi.org/10.1006/jado.1995.1045

Szablowinski, Z. (2012). Apology with and without a request for forgiveness. The Heythrop Journal, 53(5), 731-741. https://doi.org/10.1111/j.1468-2265.2011.00720.x

Tabachnick, B. G., \& Fidell, L. S. (2007). Using multivariate statistics (5 ${ }^{\text {th }}$ ed.). Boston: Pearson Education, Inc.

Tanalega, N. E., \& Gonzales, T. P. (1989). Sanggunian sa maralita [Counseling for the poor]. Manila, Philippines: Don Bosco Press.

Touissant, L. L., Marschall, J. C., \& Williams, D. R. (2012). Prospective associations between religiousness/spirituality and depression and mediating effects of forgiveness in a nationally representative sample of United States adults. Depression Research and Treatment. http://doi.org/10.1155/2012/267820

Trapnell, P. D., \& Campbell, J. D. (1999). Private self-consciousness and the five-factor model of personality: distinguishing form rumination and reflection. Journal of Personality and Social Psychology, 76(2) 284-304. https://doi.org/10.1037/0022-3514.76.2.284

Wade, N. G., Vogel, D. L., Liao, K. Y., \& Goldman, D. B. (2008). Measuring state-specific rumination: Development of the rumination about an interpersonal offense scale. Journal of Counseling Psychology, 55(3), 419-426. https://doi.org/10.1037/0022-0167.55.3.419

Welton, G. L., Hill, P. C., \& Seybold, K. S. (2008). Forgiveness in the trenches: Empathy, perspective taking and anger. Journal of Psychology and Christianity, 27(2), 168-177.

Worthington, E. L. (1998). An empathy-humility-commitment model of forgiveness applied within family dyads. Journal of Family Therapy, 20, 59-76. https://doi.org/10.1111/1467-6427.00068

Yabut, H. (2005). The phenomenology of forgiving another person (Unpublished masteral thesis). De La Salle University, Manila, Philippines. 
De Leon, M. S. L., \& Lopez, G. D.

APPENDIX A

Loadings of Correlates for Each Factor and Communalities

\begin{tabular}{|c|c|c|c|c|c|c|}
\hline Correlates & Forgiveness & Self & $\begin{array}{c}\text { Offender's } \\
\text { Behavior }\end{array}$ & Relationship & Spirituality & Communality \\
\hline Non-avoidance & .83 & & & & & .47 \\
\hline Absence of revenge & .59 & & & & & .32 \\
\hline Benevolence & .23 & & & .32 & & .28 \\
\hline Severity & & .59 & & & & .35 \\
\hline Negative emotions & & .84 & & & & .60 \\
\hline Rumination & & .91 & & & & .62 \\
\hline Attributions & & .33 & & & & .29 \\
\hline Acknowledging the offense & & & .76 & & & .39 \\
\hline Making amends & & & .79 & & & .46 \\
\hline Quality of relationship & & & & .79 & & .55 \\
\hline Commitment & & & & .92 & & .61 \\
\hline Sense of indebtedness & & & & .75 & & .57 \\
\hline Relationship of Self with God & & & & & .92 & .71 \\
\hline Spiritual appraisal of offense & & & & & .92 & .71 \\
\hline
\end{tabular}

\section{APPENDIX B}

\section{Measurement Model of Integrated Model of Forgiveness in Personal Relationships}

\begin{tabular}{|c|c|c|c|c|c|c|}
\hline Correlates & Forgiveness & Self & $\begin{array}{l}\text { Offender's } \\
\text { Behavior }\end{array}$ & Relationship & Spirituality & $\mathrm{R}^{2}$ \\
\hline Non-avoidance & $.82 *$ & & & & & .67 \\
\hline Absence of revenge & $.59 *$ & & & & & .35 \\
\hline Benevolence & $.42 *$ & & & & & .17 \\
\hline Severity & & $.62 *$ & & & & .38 \\
\hline Negative emotions & & $.85^{*}$ & & & & .72 \\
\hline Rumination & & $.87 *$ & & & & .76 \\
\hline Attributions & & $.50 *$ & & & & .25 \\
\hline Acknowledging the offense & & & $.61 *$ & & & .37 \\
\hline Making amends & & & $.99 *$ & & & .97 \\
\hline Quality of relationship & & & & $.78^{*}$ & & .61 \\
\hline Commitment & & & & $.85^{*}$ & & .72 \\
\hline Sense of indebtedness & & & & $.83^{*}$ & & .68 \\
\hline Relationship of Self with God & & & & & $.87 *$ & .75 \\
\hline Spiritual appraisal of offense & & & & & $.93 *$ & .87 \\
\hline
\end{tabular}

Spiritual appraisal of offense

\section{APPENDIX C}

Standardized Solutions of the Integrated Model of Forgiveness in Personal Relationships

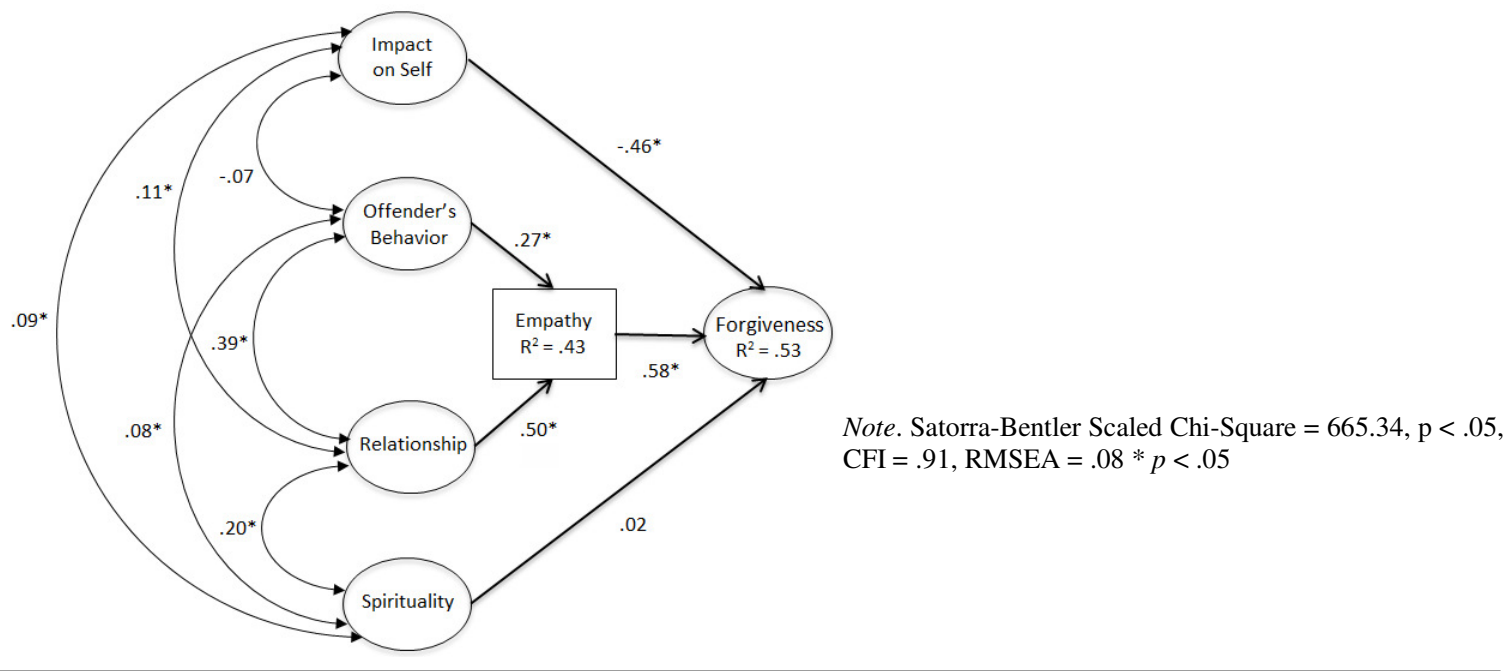

